\title{
Exploring the Issues in Policy Deployment Using SAP-LAP and eIRP Approaches: An Empirical Case Study
}

\author{
Don Plackal \\ Department of Mechanical Engineering, Sant Longowal, \\ Institute of Engineering and Technology, Longowal, Sangrur, Punjab, 148106, India. \\ E-mail: donaugusty@gmail.com \\ Sumit Kumar \\ Department of Mechanical Engineering, Sant Longowal, \\ Institute of Engineering and Technology, Longowal, Sangrur, Punjab, 148106, India. \\ Corresponding author: sumitkumar@ sliet.ac.in \\ Pardeep Gupta \\ Department of Mechanical Engineering, Sant Longowal, \\ Institute of Engineering and Technology, Longowal, Sangrur, Punjab, 148106, India. \\ E-mail: pardeepmech@yahoo.co.in
}

(Received on March 12, 2021; Accepted on August 17, 2021)

\begin{abstract}
Policy deployment refers to the formulation of policies, their implementations, and reviews. Every organization irrespective of its size and sector involves the process of policy deployment. There exist many factors that affect the process of policy deployment. These factors pose flexibilities that can alter the outcome of a policy. This paper explores the flexibilities in the choice of the factors governing a policy decision. An Indian auto-spare part industry with certain policy issues is selected for theory building. A framework model for solving the policy deployment issues is formulated using an interpretive comparative technique known as situation-actor-process-learnings-actions-performance (SAPLAP). It is based on the comparative study of contextual relationships within and among its various elements. The contextual relationship within a particular element is presented in the form of a self-interaction matrix and the contextual relationships among the elements are depicted using the cross-interaction matrix. Further, the actors and actions of the framework are ranked using an efficient interpretive ranking process (eIRP) for easy selection and prioritization. The ranks obtained through the efficient IRP model will facilitate the policymakers in the formulation of better decisions and implementation of key policies.
\end{abstract}

Keywords- Policy deployment, SAP-LAP framework, Contextual relationship, Self-interaction matrix, Cross-interaction matrix, e-IRP model.

\section{Introduction}

Today's competitive world has set forward a different paradigm for managing the business. Organizations need to adopt holistic ways for managing their policies for the attainment of goals. Hoshin Kanri (HK) a.k.a policy management (PM) or policy deployment a Japanese philosophy, is well known for handling organization-wide management. The first authentic document regarding Hoshin Kanri belongs to Akao, which is translated into English from the Japanese language in 1991. In the west, the main contributors to the origin of HK were W. Edwards Demin, who wanted to deliver his lecture on quality in the US in the 1950s. Drucker in 1954, with his book on management by objectives (MBO), described the alignment of employee's objectives with organizational objectives, and Joseph Juran, who promoted quality efforts, setting of goals for improvement, and defining quality policy in an organization. Hoshin Kanri is functional in few 
western companies, and it is designated by a variety of names. Texas Instruments names it as Administration by Policy, Xerox Corporation tags it as Control for Results, and Lucent Technologies and AT \& T label it as Policy Deployment (Matzler et al., 1996). Policy deployment involves the process of formulation of strategic policies/goals, planning the execution of these strategic policies, and reviewing them based on the results obtained. As per Jolayemi (2008), the word 'Hoshin' denotes a glowing metal, steering path, or area, while Kanri signifies administration or daily jurisdiction. Policy deployment promotes daily management activities inconsistent with the achievement of strategic objectives (Witcher and Butterworth, 1997). Policy Deployment is an all-inclusive process and considers all the workforce in its implementation aspect (Kondo, 1998; Marksberry, 2011; Nicholas, 2016) and this participative approach for developing and deploying policies and must be driven by a process of review, also it is must that policy deployment should be managed as a process. The application of Hoshin Kanri relies on a process called "catchball" to gain consensus on the deployment of Hoshin targets and measures in a team environment (Tennant and Roberts, 2001; Witcher and Butterworth, 2001). Also, policy deployment acts as a primary part of various Business Excellence Tools such as Lean, TPM, TQM, Six Sigma, etc. (Rewers and Trojanowska, 2016) and it involves many factors that interact with each other so they lay their direct and indirect effect on the outcomes.

This paper investigates the role of various factors involved in the process of policy deployment. The assortment of factors contributing to the policy deployment has to be developed for flexibility to cater to the profitability of the organization. Flexibility in policy deployment gives a special emphasis on manufacturing cost reduction, manpower optimization, and reduction of MUDAs. This paper first identifies the research gap with the help of a brief literature survey and then a case study is developed using factors extracted from the literature survey. The SAP-LAP approach has been adopted to analyze organizational situations followed by a ranking of factors with the help of an eIRP model. A special focus has been made on the aspect of flexible linkages concerning the process of policy deployment.

\section{Literature Review}

Policy Deployment or Hoshin Kanri is a scheduling, execution, and review framework for systematically considered amendments or changes in an organization. The principle of policy deployment is to construct activities of the daily management which are reliable by means of the attainment of a small number of essential planned primary issues surrounded by a stipulated time frame (Witcher and Butterworth, 1997). Policy Deployment starts from the plant manager who sets the annual policy and then passes it on to the section manager of each department of the firm which in turn reaches the foreman and line actors who convert the strategic plans into actions (Dale, 1990). The whole process of policy deployment is centered on a process known as Catch ball. The Catch ball process refers to the bi-directional sharing of information, which involves the flow of the information from higher-level employees to the lower level and vice versa using a feedback mechanism. The main objective of the catch ball is to transform the annual policies of the organization into the self-determined goals of the employees (Tennant and Roberts, 2001). The catchball process can be used to build consensus so that policy can be implemented successfully (Watson, 1998). The answer to policy deployment is that it ushers the entire institution into the deliberate forecast progression both top-down and bottom-up. It makes sure the route, targets, and intentions of the institution are realistically urbanized, skillfully distinct, undoubtedly conveyed, and tailored according to the system feedback. This scheme incorporates equipment for incessant enhancement, developments, and functioning (Witcher, 2014). Xerox (1992) defined the strategic operation as: "An input which is capable of expressing and communicating the visualization, 
undertaking, goals, and essential programs to every employee". It answered two queries: "What tasks are we going to carry out?" and "How are we going to complete those tasks? Policy Deployment is a comprehensive process that involves all the employees in its functioning aspect and helps in integrating strategies with daily actions (Nicholas, 2016). The approach of policy deployment overcomes the generic problems of strategic management by networking employees with managers, thereby enabling both horizontal as well as vertical communication (Akao, 2004). A significant strength of strategic planning is its supplementary aspect of flexibility that emerges from the regular utilization of Deming's PDCA method. The organization first needs to become accustomed to the plan, reorganize its assets according to the plan, realign actions according to new strategies and then strive to enhance operation performance (Mulligan et al., 1996).

The authors Witcher and Butterworth (1999) presented the (FAIR) model for the deployment of policies in an organization. This model follows stages of Focus-Alignment-Integrate-ApproachReview for the deployment of policies. One of the major outcomes of policy deployment is the annual policy and (Manos, 2010) in his study presented practical tips, tricks, and advice for Hoshin promotion in an organization to establish its yearly policy. The policy deployment employs policy management and daily management. The first one works for breakthrough management and the latter for managing the daily targets (Lee and Dale, 1998). Kumar and Gupta (2021) discussed the implementation of a cost management initiative in an automotive organization. The author reported that the adopted cost management initiatives were included in the vision and mission statements as a part of policy management. The authors also discussed the role of daily management in achieving the annual targets. The methodology of the policy deployment involves a two-way approach i.e .both top-down as well as bottom-up. In the top-down approach, the long-term actions or goals are put into action whereas, in a bottom-up approach, necessary actions are put to use after the criticism through feedback mechanism is obtained from the subordinate level employees (Ahmed, 2016). The role of TQM in policy management practices was analyzed by comparing the application in both Japanese and American companies and it was found that TQM is every effect in the implementation of policy management (Cwiklicki, 2010). Marksberry (2011) gave a detailed analysis of Toyota's policy deployment strategies using both classical and modern tactical planning methods. The strategic planning methodology which is an integral component of Hoshin Kanri was analyzed with the help of the Dijkstra algorithm for optimization of the delivery and scheduling from the perspectives of industrial Engineering and stakeholders (Ho and Soebandrija, 2021). To manage policies in a firm, a holistic framework is required that should contain the fundamental entities in terms of the professional environment and their connected administrative functions along with attributes. Any professional or managerial environment of an organization consists of a situation to be analyzed, the actors and their role which are intended to improve the current prevailing situations through various processes (SAP). The interaction of these situations, actors, and processes steers to learning, action, and performance (LAP) (Sushil, 2001a). Many researchers applied the SAP-LAP modelling approach for analyzing situations in various scenarios (Majumdar and Gupta, 2001; Husain et al., 2002; Kak, 2004; Arshinder et al., 2007; Garg and Deshmukh, 2010; Kumar and Gupta, 2020). The deployment of e-commerce technology in the Indian car manufacturing industries was analyzed with the help of the SAP-LAP model of inquiry (Majumdar and Gupta, 2001). Husain et al. (2002) analyzed case studies of three establishments that cooperated in the post-Indian independence (i.e., after 1947) stage and after the economic reforms began (i.e., after 1985) using the SAP-LAP framework. The author Kak (2004) analyzed the case studies of two medical institutions to address the issues of competitiveness, managerial aspects, policy development, and flexibilities involved in the policy development with the help of the SAP-LAP framework. The SAP-LAP framework has also been adopted to address the coordination issues in 
the supply (Arshinder et al., 2007; Kabra and Ramesh, 2015; Kumar and Anbanandam, 2020). This technique has also been applied for the assessment of IT operation of Indian SMEs (Thakkar et al., 2008). In a very interesting case, the SAP-LAP framework was adopted to explore the flexibility in the maintenance work of an organization (Garg and Deshmukh, 2010). The authors Malik et al. (2019) analyzed the fiscal enclosure in India with the help of SAP-LAP framework and construed the relationship between various elements of the framework with the help of interpretive ranking process. The authors (Gupta and Suri, 2018) employed the SAP-LAP framework for analyzing the E-governance projects that are aimed to benefit the planners and implementers in making decisions.

The above brief literature review presents the picture about the role of policy deployment in an organization and various methodologies to implement the process of policy deployment. The literature review also presents the various scenarios where the qualitative interpretive tool SAPLAP and interpretive ranking approaches are utilized to analyze and rank certain parameters of interest.

\subsection{Research Gap}

It has been observed from the brief literature review that no interactive model of policy deployment is available that addresses the flexibilities involved in the process. The authors in this paper present the SAP-LAP model of a policy deployment in a case organization. The analysis is further extended by ranking the factors of interest.

\subsection{Research Objectives}

The aim of this paper is to present a systematic interpretive approach for policy deployment. The following are the objectives of the proposed research.

(i) Identification of factors in the form of Situations (ST), Actors (AT), and Processes (PR) that affect the process of policy deployment.

(ii) Identification of Learnings (LN), Actions (AN) contribute to the policy deployment along with the identification of Performance objectives (PM) that the organization wants to achieve.

(iii) To study the interactions among the above-identified SAP-LAP factors.

(iv) To rank the actors with respect to process and actions with respect to performance objectives using efficient Interpretive Process (eIRP).

\section{About the Organization}

The organization XYZ ltd. (name changed) is an Indian manufacturer of vehicle machinery like water pumping power steering systems, physical navigation and postponement systems, valve train components, friction material products, steering support and power-assisted steering, safety belt systems, and pressure casting commodities.

\section{Methodology}

An SAP-LAP model of inquiry is adopted for exploring the role of factors responsible for policy deployment in an automotive spare part industry. A thorough study of various literature reviews and annual reports of the $\mathrm{ABC}$ ltd. the company was done. First of all, the prevailing situations on the policy formulation that will drive a firm to achieve business excellence were assessed with special focus given to the aspect of flexibility. Thereafter, the actors who understand the situation are identified. The identification of the process elements of the framework involves the identification of corporeal flow, knowledge flow, resource flow, command flow, capital flow, and aid. The actors are supposed to possess a role in these processes. 
The interplay of the SAP analysis is done using the self-interaction and cross interaction tables. The second phase of the analysis is known as LAP synthesis. In this phase, learning issues are identified from the records of the organization, and based on these learning issues, the actions are suggested. Performance parameters are also chosen to map actions and learning.

\subsection{Identification of SAP-LAP Elements}

The identification of the SAP elements is a foremost process that leads to the development of the policy management framework. The elements are identified from the organization literature and telephonic conversation. Table 1 shows the various elements of the SAP-LAP framework.

Table 1. Elements of SAP-LAP framework.

\begin{tabular}{|c|c|}
\hline Components & Elements \\
\hline \multirow{3}{*}{ Situation } & ST1 - Stiff Competition \\
\hline & ST2 - Poor Quality issues \\
\hline & ST3 - Maintaining customer goodwill. \\
\hline \multirow{4}{*}{ Actor } & AT1- CEO \\
\hline & AT2 - Plant Head \\
\hline & AT3 - Employees \\
\hline & AT4 - Customers \\
\hline \multirow{5}{*}{ Process } & PR1 - Strategic Planning \\
\hline & PR2-Customer Focus \\
\hline & PR3 - Cost Management \\
\hline & PR4 - Communication \\
\hline & PR5 -Total Employee Involvement \\
\hline \multirow{4}{*}{ Learning } & LN1 - Consistency in the market \\
\hline & LN2 - Overall image \\
\hline & LN3 - Quality Norms \\
\hline & L4- Innovation Culture \\
\hline \multirow{4}{*}{ Actions } & AN1 - QIT (Quality Improvement Teams) \\
\hline & AN2 - Inception of Coverage Ratio (CR) and Hit Ratio (HR) \\
\hline & AN3 - Strategic Business Plan meetings \\
\hline & AN4- TQM meetings \\
\hline \multirow{3}{*}{ Performance } & PM1 - Sustainable economic benefit \\
\hline & PM2 - Consumer Contentment \\
\hline & PM3 - Customer Focus Training (CFT) \\
\hline
\end{tabular}

\subsection{Interactions among the SAP-LAP Elements}

The following section presents the discussion about the various interactions between the SAP-LAP elements.

\subsection{Self-Interaction of SAP Elements}

The self-interaction matrices are worn to assess the interdependence of dealings among its various elements. It is represented in two different forms, i.e., Binary and interpretive forms. In the binary form, 1 is used to denote the interaction among the two elements, whereas 0 represents no interactions among the elements (Sushil, 2005). The self-interaction among the various elements for the given situation, actors, and processes are presented in Table 2 to Table 6 in both binaries as well as interpretive form. The relationships among the different elements of the matrix are either based on judgment or experience (Sushil, 2017b). 
Table 2. Self-interaction binary matrix for situations in binary form.

\begin{tabular}{|c|c|c|}
\hline 1 & 1 & ST1 \\
\hline 0 & ST2 & \\
\hline ST3 & & \\
\hline
\end{tabular}

Table 3. Self-interaction interpretive matrix for a situation in interpretive form.

\begin{tabular}{|c|c|c|}
\hline Progressive growth of the organization & Non-Defective end product & ST1 \\
\hline-- & ST2 & \\
\hline ST3 & & \\
\hline
\end{tabular}

From Table 2 and Table 3, it is clear that situation S1 is the most interactive among the others. There is no interaction between the situation S2 and S3. When situation S1 influences S2, the result obtained is the non-defective end product. Similarly, the interrelationship between S1 with S3 contributes to the progressive growth of the organization.

Table 4. Self-interaction binary matrix for actors in binary form.

\begin{tabular}{|c|c|c|c|}
\hline 1 & 0 & 1 & AT1 \\
\hline 1 & 1 & AT2 & \\
\hline 0 & AT3 & & \\
\hline AT4 & & & \\
\hline
\end{tabular}

Table 5. Self-interaction interpretive matrix for actors in interpretive form.

\begin{tabular}{|c|c|c|c|}
\hline Feedback generated & -- & Strategic Planning & AT1 \\
\hline Policy Deployment and Support & Review Process & AT2 & \\
\hline-- & AT3 & & \\
\hline AT4 & & & \\
\hline
\end{tabular}

The self-interaction matrix for the actors is presented in Table 4 and Table 5. From these exhibits, it can be seen that how one actor interacts with the other. Actor A1 and A2 are the most interactive actor among the others. The actor A1 while interacting with A2 helps in strategic planning. Similarly, actors A2 and A4 interact mutually for policy deployment and support.

Table 6. Self-interaction binary matrix for process in binary form.

\begin{tabular}{|c|c|c|c|c|}
\hline 1 & 1 & 1 & 1 & PR1 \\
\hline 0 & 0 & 0 & PR2 & \\
\hline 0 & 0 & PR3 & & \\
\hline 1 & PR4 & & & \\
\hline PR5 & & & & \\
\hline
\end{tabular}

Table 7. Self-interaction interpretive matrix for process in interpretive form.

\begin{tabular}{|c|c|c|c|c|}
\hline Competence Up-gradation & Quality Improvement. & Overall market share growth. & Problem Solutions & RP1 \\
\hline--- & ---- & --- & PR2 & \\
\hline---- & ---- & PR3 & & \\
\hline Manufacturing Cost Reduction & PR4 & & & \\
\hline PR5 & & & & \\
\hline
\end{tabular}


The self-interaction matrix for the actors is presented in Table 4 and Table 5. From these exhibits, it can be seen that how one actor interacts with the other. Actor A1 and A2 are the most interactive actor among the others. The actor A1 while interacting with A2 helps in strategic planning. Similarly, actors A2 and A4 interact mutually for policy deployment and support. Table 6 and Table 7 presents the self-interaction matrices for the process. Process P1 is the most interacting process among others. Process P1 and P4 interact for quality improvement. Similarly, processes P1 and P5 interact for competence up-gradation.

\subsection{Cross Interaction Matrix between SAP-LAP Elements}

In the cross-interaction matrix, the interrelationship in the elements of the SAP-LAP framework is studied. Table 8 to Table 13 presents the various cross-interaction matrices.

Table 8. Cross interaction binary matrix for situation and actors in binary form.

\begin{tabular}{|c|c|c|c|c|}
\hline Situations & \multicolumn{5}{|l|}{} \\
\hline ST1 & 1 & 1 & 0 & 0 \\
\hline ST2 & 1 & 1 & 0 & 0 \\
\hline ST3 & 1 & 0 & 0 & 1 \\
\hline Actors & AT1 & AT2 & AT3 & AT4 \\
\hline
\end{tabular}

Table 9. Cross interaction interpretive matrix for situation and actors in interpretive form.

\begin{tabular}{|c|c|c|c|c|}
\hline Situations & \multicolumn{4}{|c|}{} \\
\hline ST1 & Strategic Goals and Plans & $\begin{array}{c}\text { Developing } \\
\text { innovative solutions }\end{array}$ & $\begin{array}{c}---- \\
-\end{array}$ & ---- \\
\hline ST2 & Provision of New Technology & $\begin{array}{c}\text { Policy and Clearances } \\
\text { formulation }\end{array}$ & ----- & - \\
\hline ST3 & Constant interaction with the customers & ---- & ----- & Understanding the customer needs \\
\hline Actors & AT1 & AT2 & AT3 & AT4 \\
\hline
\end{tabular}

Table 8 and Table 9 presents the cross interaction between situation and actors in binary and interpretive form respectively. From these matrices, it is clear that actor A1 is the most influencing actor since it interacts with all situations. Actor A1 performs the role of developing strategic goals and plans.

Table 10. Cross interaction binary matrix for actors and process in binary form.

\begin{tabular}{|c|c|c|c|c|c|}
\hline Actors & \multicolumn{5}{|l|}{} \\
\hline AT1 & 1 & 1 & 1 & 1 & 1 \\
\hline AT2 & 1 & 1 & 1 & 1 & 1 \\
\hline AT3 & 0 & 0 & 1 & 1 & 1 \\
\hline AT4 & 0 & 1 & 1 & 0 & 0 \\
\hline Process & PR1 & PR2 & PR3 & PR4 & PR5 \\
\hline
\end{tabular}

Table 10 and Table 11presents the cross interaction between actors and processes in binary and interpretive form respectively. From these matrices, it is clear that actor A1 is the most linked actor in the policy execution of various strategies. Actor A1 is responsible for the felicitation of different information flow and order flow in an organization and is also responsible for the continuous improvement of activities. 
Table 11. Cross interaction interpretive matrix for actors and process in interpretive form.

\begin{tabular}{|c|l|l|l|l|l|}
\hline Actors & \multicolumn{5}{|l|}{} \\
\hline AT1 & $\begin{array}{l}\text { Visions and } \\
\text { Missions }\end{array}$ & $\begin{array}{l}\text { Competence } \\
\text { Building }\end{array}$ & Ensuring Profitability & $\begin{array}{l}\text { Smooth Flow of the } \\
\text { Work Process }\end{array}$ & $\begin{array}{l}\text { Continuous improvement } \\
\text { of activities }\end{array}$ \\
\hline AT2 & Setting KPI & Efficient Process & $\begin{array}{l}\text { Manpower } \\
\text { Optimization }\end{array}$ & $\begin{array}{l}\text { Active participation } \\
\text { of workers }\end{array}$ & $\begin{array}{l}\text { Policy } \\
\text { Strategy }\end{array}$ \\
\hline AT3 & --- & ---- & Reduction of MUDAs & Moral Enhancement & Progressive Growth \\
\hline AT4 & ---- & Customer Goodwill & Forecast Sales & ----- & ----- \\
\hline Process & PR1 & PR2 & PR3 & PR4 & PR5 \\
\hline
\end{tabular}

Table 12. Cross interaction binary matrix for action and performance.

\begin{tabular}{|c|c|c|c|}
\hline Actions & \multicolumn{3}{|c|}{} \\
\hline AN1 & 1 & 1 & 1 \\
\hline AN2 & 1 & 0 & 0 \\
\hline AN3 & 1 & 1 & 1 \\
\hline AN4 & 1 & 0 & 0 \\
\hline Performance & PM1 & PM2 & PM3 \\
\hline
\end{tabular}

Table 13. Cross interaction interpretive matrix for actions and performance in interpretive form.

\begin{tabular}{|c|l|l|l|}
\hline Actions & \multicolumn{2}{|l|}{} \\
\hline AN1 & Quality Control & Prospective Business & Quality Enhancement \\
\hline AN2 & Competitive Advantage & -- & -- \\
\hline AN3 & Developing Technological Solutions & Customer Goodwill & Business Expansion \\
\hline AN4 & In-house Technology Development & -- & -- \\
\hline Performance & PM1 & PM2 & PM3 \\
\hline
\end{tabular}

Table 12 and Table 13 displays the cross interaction between actions and performance in binary and interpretive form respectively. From these matrices, it is clear that the suggested action of the quality Improvement team (AN1) carries the highest weightage for enhancing the various expected performance parameters. The cross interaction between action and performance focuses on eliminating discontinuities in manufacturing systems. The interaction helps in bringing stability in production, increase efficiency, and elasticity by the elimination of waste.

\section{5 e-IRP Model}

IRP model uses an interpretive matrix as a fundamental instrument to compare the interpretive interactions in the matrix through pairwise comparison. In IRP, the expert makes a sound interpretation for the domination of one element over the other all through the paired comparison and reduces the burden of experts in a pronouncement-making process (Sushil, 2001b). Ranks obtained in the IRP method will augment the policymakers to formulate an enhanced tactical judgment before implementing policies.

The amount of paired comparisons obtained in an IRP model is $m^{*} n *(n-1) / 2$ where $m$ denotes the orientation variables and $n$ denotes the ranking variable. The efficient IRP procedure improves the limitations on SAP-LAP linkages and the IRP models (Sushil, 2019). The research adopted the SAP-LAP based efficient IRP model for the given case study. The efficient IRP model will trim down the paired comparisons by incorporating transitive, implicit, and non-implicit dominance matrices (Sushil, 2019). The efficient IRP model gives an interpretive matrix and interpretive understanding base judgment framework which will be obliging for the senior managers in developing strategies and executing them. The detailed procedures implicated in an efficient 
interpretive ranking process required for policy deployment of the given case organization is illustrated pace by pace as given below (Sushil, 2017a).

\subsubsection{Detection of Variables}

In this step, two sets of variables are acknowledged in which the initial set of variables consists of the alternatives that have to be ranked with reference to the other set of variables which is usually nominated as the criterion. The selected actors of the organization designated as AT1, AT2, AT3, and AT4 are ranked for their processes listed as PR1, PR2, PR3, PR4, and PR5 respectively. Correspondingly, the actions designated as AN1, AN2, AN3, and AN4 are ranked to their performance designated as PM1, PM2, and PM3 correspondingly.

\subsubsection{Paired Comparison}

At this juncture, the interpretive cross interaction matrix is used as a base to evaluate among the assorted alternatives to discover which element is dominating the other element for the given criterion. Here the actor AT1 is compared with AT2 using the interpretive matrix for the interaction

Table 14. Knowledge base ranking of actors and processes.

\begin{tabular}{|c|c|c|}
\hline+ & Interaction With Process & Interpretive Logic \\
\hline \multirow{2}{*}{ AT1 Dominating AT2 } & PR1 & $\begin{array}{l}\text { Visions and Missions have more influence than the setting of } \\
\text { the Key Performance Indicators. }\end{array}$ \\
\hline & PR2 & $\begin{array}{l}\text { Competence Building is more important than ensuring an } \\
\text { efficient work process. }\end{array}$ \\
\hline \multirow{5}{*}{ AT1 Dominating AT3 } & PR1 & A3 is not having any direct influence \\
\hline & PR2 & $\mathrm{A} 3$ is not having any direct influence \\
\hline & PR3 & $\begin{array}{l}\text { Ensuring Profitability is more important than the Reduction of } \\
\text { MUDAs. }\end{array}$ \\
\hline & PR4 & $\begin{array}{l}\text { Smooth flow of the work process is more important than } \\
\text { Reduction of MUDAs. }\end{array}$ \\
\hline & PR5 & $\begin{array}{l}\text { Continuous improvement of the activities process is more } \\
\text { important than Progressive Growth. }\end{array}$ \\
\hline \multirow{3}{*}{ AT1 Dominating AT4 } & PR1 & A4 is not having any direct influence \\
\hline & PR4 & A4 is not having any direct influence \\
\hline & PR5 & A4 is not having any direct influence \\
\hline \multirow{3}{*}{ AT2 Dominating AT1 } & PR3 & $\begin{array}{l}\text { Manpower optimization leads to ensuring profitability hence it } \\
\text { has more dominance. }\end{array}$ \\
\hline & PR4 & $\begin{array}{l}\text { The active participation of the workers is more important than } \\
\text { the smooth flow of the work process. }\end{array}$ \\
\hline & PR5 & $\begin{array}{l}\text { Policy Management Strategy has more influence than the } \\
\text { continuous improvement of activities }\end{array}$ \\
\hline \multirow{5}{*}{ AT2 Dominating AT3 } & PR1 & A3 is not having any direct influence \\
\hline & PR2 & A3 is not having any direct influence \\
\hline & PR3 & $\begin{array}{l}\text { Manpower optimization has more influence than the Reduction } \\
\text { of MUDAs. }\end{array}$ \\
\hline & PR4 & $\begin{array}{l}\text { Active Participation of workers has more influence than Morale } \\
\text { Enhancement. }\end{array}$ \\
\hline & PR5 & $\begin{array}{l}\text { Policy Management Strategy is more important than } \\
\text { Progressive Growth. }\end{array}$ \\
\hline \multirow{3}{*}{ AT2 Dominating AT4 } & PR1 & A4 is not having any direct influence \\
\hline & PR4 & A4 is not having any direct influence \\
\hline & PR5 & A4 is not having any direct influence \\
\hline AT3 Dominating AT4 & PR3 & Reduction of MUDAs has more influence than forecast sales \\
\hline \multirow{2}{*}{ AT4 Dominating AT1 } & PR3 & Forecast Sales have more influence than ensuring profitability. \\
\hline & PR2 & A1 is not having any direct influence. \\
\hline \multirow{2}{*}{ AT4 Dominating AT2 } & PR2 & Customer Goodwill is more important than an efficient process. \\
\hline & PR3 & Forecast Sales are more important than manpower optimization. \\
\hline AT4 Dominating AT3 & PR2 & A3 is not having any direct influence. \\
\hline
\end{tabular}


with various processes such as PR1, PR2, PR3, etc. to find out the interpretive logic of the paired comparison. The paired comparison creates a knowledge base ranking. The knowledge base ranking of various actors for their process and actions concerning performance are illustrated in Table 14 and Table 15 respectively.

Table 15. Knowledge base ranking of actions and performance parameters.

\begin{tabular}{|l|c|l|}
\hline \multicolumn{1}{|c|}{ Paired Comparison } & Interaction With Performances Parameters & \multicolumn{1}{|c|}{ Interpretive Logic } \\
\hline \multirow{2}{*}{ AN1 Dominating AN2 } & PM3 & AN2 is not having any direct influence. \\
\cline { 2 - 3 } AN1 Dominating AN3 & PM2 & $\begin{array}{l}\text { AN2 is not having any direct influence. } \\
\text { than Business Expansion. }\end{array}$ \\
\hline AN1 Dominating AN4 & PM3 & AN4 is not having any direct influence \\
\cline { 2 - 3 } AN2 Dominating AN1 & PM2 & AN4 is not having any direct influence. \\
\hline \multirow{3}{*}{ AN3 Dominating AN2 } & PM3 & $\begin{array}{l}\text { Competitive Advantage is more important than } \\
\text { Quality Control. }\end{array}$ \\
\cline { 2 - 3 } & PM1 & $\begin{array}{l}\text { Developing Technological Solutions is more } \\
\text { important than giving a competitive advantage } \\
\text { over the product. }\end{array}$ \\
\cline { 2 - 3 } AN3 Dominating AN1 & PM1 & AN2 is not having any direct influence. \\
\cline { 2 - 3 } & PM2 & $\begin{array}{l}\text { Developing Technological Solutions is more } \\
\text { important than Quality Control. }\end{array}$ \\
\hline \multirow{3}{*}{ AN3 Dominating AN4 } & PM3 & $\begin{array}{l}\text { Customer Goodwill is given more priority over } \\
\text { the Prospective Business. }\end{array}$ \\
\cline { 2 - 3 } & PM1 & $\begin{array}{l}\text { Developing Technological Solutions has more } \\
\text { influence than In-house } \\
\text { Development. }\end{array}$ \\
\cline { 2 - 3 } & PM2 & AN4 is not having any direct influence. \\
\hline \multirow{2}{*}{ AN4 Dominating AN1 } & PM1 & $\begin{array}{l}\text { AN4 is not having any direct influence. } \\
\text { influence than ensuring profitability. }\end{array}$ \\
\hline
\end{tabular}

\subsubsection{Dominating Interaction Matrix}

The dominating interaction matrix is geared up for showing the dominance of one variable with reference to the other variables for a given choice. The ground rules of dominance matrix preparation are taken from the fuzzy set logic (Alley et al., 1979).

\subsubsection{Ranking of Actors with Respect to Different Processes}

The pairwise comparison for actors with reference to the various process is done to study the dominance of one actor over the other for a given process. The dominance interaction of the paired wise actors for the given process is depicted in Table 16 to Table 20. Table 24 shows the color coding scheme adopted for highlighting the various types of dominance.

Table 16. Dominating interaction matrix of actors for process PR1.

\begin{tabular}{|c|c|c|c|c|}
\hline & AT1 & AT2 & AT3 & AT4 \\
\hline AT1 & & 1 & 1 & 1 \\
\hline AT2 & --- & & 1 & 1 \\
\hline AT3 & --- & ---- & & 0 \\
\hline AT4 & --- & --- & -- & \\
\hline
\end{tabular}


Table 17. Dominating interaction matrix of actors for process PR2.

\begin{tabular}{|c|c|c|c|c|}
\hline & AT1 & AT2 & AT3 & AT4 \\
\hline AT1 & & 1 & 1 & -- \\
\hline AT2 & -- & & 1 & -- \\
\hline AT3 & -- & -- & 1 & \\
\hline AT4 & $*$ & 1 & & \\
\hline
\end{tabular}

Table 18. Dominating interaction matrix of actors for process PR3.

\begin{tabular}{|c|c|c|c|c|}
\hline & AT1 & AT2 & AT3 & AT4 \\
\hline AT1 & & -- & 1 & -- \\
\hline AT2 & 1 & & 1 & 1 \\
\hline AT3 & -- & -- & & - \\
\hline AT4 & 1 & $1^{*}$ & -- & \\
\hline
\end{tabular}

Table 19. Dominating interaction matrix of actors for process PR4.

\begin{tabular}{|c|c|c|c|c|}
\hline & AT1 & AT2 & AT3 & AT4 \\
\hline AT1 & & -- & 1 & 1 \\
\hline AT2 & 1 & & 1 & 0 \\
\hline AT3 & -- & -- & & 1 \\
\hline AT4 & -- & -- & -- & \\
\hline
\end{tabular}

Table 20. Dominating interaction matrix of actors for process PR5.

\begin{tabular}{|c|c|c|c|c|}
\hline & AT1 & AT2 & AT3 & AT4 \\
\hline AT1 & & -- & 1 & 1 \\
\hline AT2 & & & 1 & 0 \\
\hline AT3 & -- & -- & & \\
\hline AT4 & -- & -- & -- & \\
\hline
\end{tabular}

\subsubsection{Ranking of Actions with Respect to different Performances}

The pairwise comparison for actions with reference to the various performances is done to study the dominance of one action over the other for a given performance. The dominance interaction of the paired wise actions for the given performances is as depicted in Table 21 to Table 23.

Table 21. Dominating interaction matrix of actions for performance PM1.

\begin{tabular}{|c|c|c|c|c|}
\hline & AN1 & AN2 & AN3 & AN4 \\
\hline AN1 & & -- & -- & -- \\
\hline AN2 & 1 & & -- & 1 \\
\hline AN3 & 1 & 1 & & -- \\
\hline
\end{tabular}

Table 22. Dominating interaction matrix of actions for performance PM2.

\begin{tabular}{|c|c|c|c|c|}
\hline & AN1 & AN2 & AN3 & AN4 \\
\hline AN1 & & 1 & -- & 1 \\
\hline AN2 & -- & & -- & 0 \\
\hline AN3 & 1 & 1 & -- & 1 \\
\hline AN4 & -- & -- & - & \\
\hline
\end{tabular}


Table 23. Dominating interaction matrix of actions for performance PM3.

\begin{tabular}{|c|c|c|c|c|}
\hline & AN1 & AN2 & AN3 & AN4 \\
\hline AN1 & & 1 & 1 & 0 \\
\hline AN2 & -- & & & 1 \\
\hline AN3 & -- & 1 & -- & \\
\hline AN4 & -- & -- & & \\
\hline
\end{tabular}

Table 24. Color scheme.

\begin{tabular}{|c|c|}
\hline 1 & Implicit dominance \\
\hline 0 & Implicit non-dominance \\
\hline 1 & Interpretive dominance \\
\hline 1 & Transitive dominance \\
\hline-- & No interaction \\
\hline & Same element \\
\hline
\end{tabular}

Here the efficient IRP model is applied which takes into account the transitive and implicit dominance to reduce the number of paired comparisons (Sushil, 2019). Table 25 shows which actors are being dominated or dominating with reference to the other actors for a given process.

Table 25. Dominating interaction matrix - ranking of actors with reference to the process.

\begin{tabular}{|c|c|c|c|c|c|}
\cline { 2 - 6 } \multicolumn{4}{c|}{} & \multicolumn{5}{c|}{ Dominating } \\
\hline \multirow{4}{*}{ Being Dominated } & & AT1 & AT2 & AT3 & AT4 \\
\cline { 2 - 6 } & AT1 & - & PR1,PR2 & PR1,PR2,PR3,PR4,PR5 & PR1,PR4,RP5 \\
\cline { 2 - 6 } & AT2 & PR3,PR4,PR5 & & PR1,PR2,PR3,PR4,PR5 & PR1,PR4,PR5 \\
\cline { 2 - 6 } & AT3 & - & - & - & PR3 \\
\cline { 2 - 6 } & AT4 & PR3,PR2 & PR2,RP3 & PR2 & - \\
\hline
\end{tabular}

Table 26 shows which actions are being dominated or dominating with reference to the other actions for a given performance parameter.

Table 26. Dominating interaction matrix - ranking of actions with reference to the performance.

\begin{tabular}{|c|c|c|c|c|c|}
\cline { 2 - 6 } \multicolumn{1}{c|}{} & \multicolumn{5}{c|}{ Dominating } \\
\hline \multirow{4}{*}{ Being Dominated } & & AN1 & AN2 & AN3 & AN4 \\
\cline { 2 - 6 } & AN1 & - & PM3, PM2 & PM3 & PM2, PM3 \\
\cline { 2 - 6 } & AN2 & PM1 & - & - & - \\
\cline { 2 - 6 } & AN3 & PM1, PM2 & PM1, PM2, PM3 & - & PM1, PM2, PM3 \\
\cline { 2 - 6 } & AN4 & PM1 & - & - & - \\
\hline
\end{tabular}

From Table 25, it can be seen that the actor AT1, AT2, AT3, and AT4 is dominating a total of $10,11,1$ and 6 interactions respectively which is denoted by D. Correspondingly, the actors AT1, AT2, AT3, and AT4 is being dominated by a total of 5,4,10 and 7 interactions respectively which is denoted by the variable B. From Table 26, it can be seen that the actions AN1, AN2, AN3, and AN4 is dominating a total of $5,1,8$ and 1 interaction respectively which is denoted by $D$. Correspondingly, the actions AN1, AN2, AN3, and AN4 is being dominated by a total of 4,5,1, and 5 interactions respectively which are denoted by the variable B. 


\subsubsection{Dominance Matrix}

The dominance matrix is organized from the various interactions taking place from the elements of the dominance interaction matrix. The sum of the interactions taking place in a row is designated as $\mathrm{D}$ whereas the sum of the interactions taking place in a column is designated as $\mathrm{B}$ and the net dominance is depicted by (D-B). The value of (D-B) determines the rank of an element concerning its various choices i.e., which element dominates the other for a given process. The rank having the highest positive net dominance is ranked as I (Alley et al., 1979). The higher the negative value of (D-B) the lower is the rank and vice versa. The dominance matrix for actors for the process and actions for its performances is designated as shown below.

Table 27. Dominance matrix ranking of actors for process.

\begin{tabular}{|c|c|c|c|c|c|c|c|}
\hline & AT1 & AT2 & AT3 & AT4 & $\begin{array}{c}\text { Dominating } \\
\text { Cases (D) }\end{array}$ & Net Dominance (D-B) & $\begin{array}{c}\text { Grade } \\
\text { Dominating }\end{array}$ \\
\hline AT1 & --- & 2 & 5 & 3 & 10 & 5 & II \\
\hline AT2 & 3 & --- & 5 & 3 & 11 & 7 & I \\
\hline AT3 & --- & --- & --- & 1 & 1 & -10 & IV \\
\hline AT4 & 2 & 2 & 1 & --- & 5 & III \\
\hline No. Being dominated (b) & 5 & 4 & 11 & 7 & \multicolumn{3}{|c|}{27 (Net interactions) } \\
\hline
\end{tabular}

From Table 27, the inference of the rank of actors with reference to various processes can be deduced. The actor $\mathrm{A} 1$ or CEO is ranked I as the actor A1 is having the highest net dominance rank or (D-B) value. Actor A3 or the plant head is ranked IV as it is having the least net dominance rank or (D-B) value.

Table 28. Dominance matrix ranking of actions for performance.

\begin{tabular}{|c|c|c|c|c|c|c|c|}
\hline & AN1 & AN2 & AN3 & AN4 & Total Dominating (D) & Total Dominance (D-B) & $\begin{array}{c}\text { Grade } \\
\text { Dominating }\end{array}$ \\
\hline AN1 & --- & 2 & 1 & 2 & 5 & 1 & II \\
\hline AN2 & 1 & --- & 0 & 0 & 1 & -4 & III \\
\hline AN3 & 2 & 3 & --- & 3 & 8 & -4 & I \\
\hline AN4 & 1 & -- & --- & --- & 1 & III \\
\hline No. Being dominated (b) & 4 & 5 & 1 & 5 & \multicolumn{2}{|c|}{15 (Net Interactions) } \\
\hline
\end{tabular}

Correspondingly, from Table 28, the rank of actions with reference to the various process can be deduced. The action AN3 is having the highest rank with the highest positive net dominance value of 7 whereas the action AN2 and AN4 are having the lowest rank of III with the net dominance value of -4 .

\subsubsection{Development of the IRP Model}

The ranks obtained in support of different processes are illustrated with an Interpretive Ranking Model as revealed below for various actors with reference to its process and actions to perform. The arrows depicted in the IRP model denotes which actor dominates the other for different processes and which actions dominate the other for different performances. The element pointed towards the head of the arrow is being dominated by the other one. Figure 1 and Figure 2 show the IRP model for actors with reference to process and actions with reference to performance respectively. The ranks deduced from the given efficient IRP model will make it easier for the management of the case organization to make policies that will enhance the operational performance of the business. From Figure 1, it can be inferred that actor A2 or the plant head is the most influential actor with respect to various processes in the case organization. Correspondingly from Figure 2, it can be made out that the action AN3 of strategic business planning is the most 
influential action for implementing the policy deployment of the case organization.

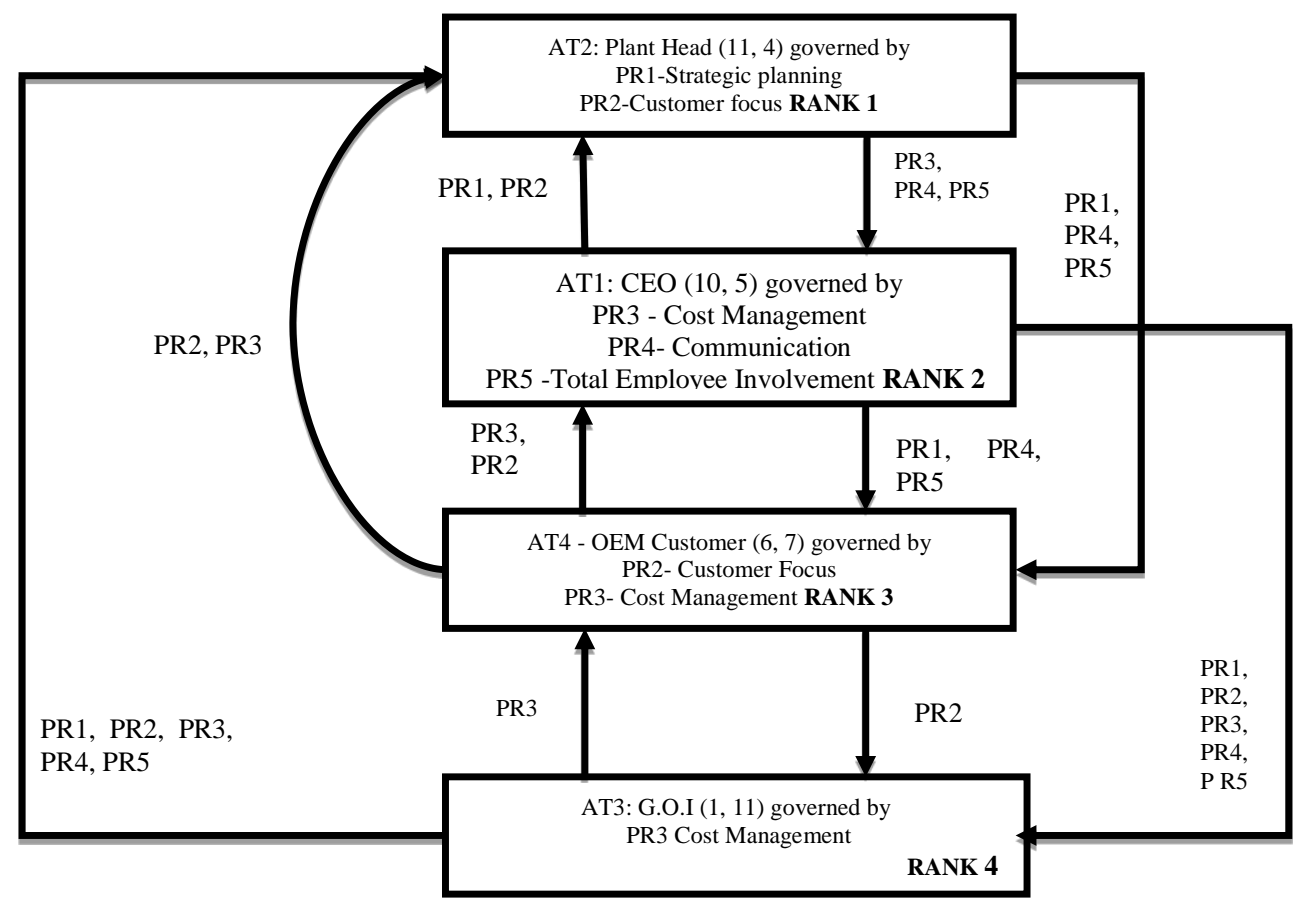

Figure 1. IRP model for actors with reference to process.

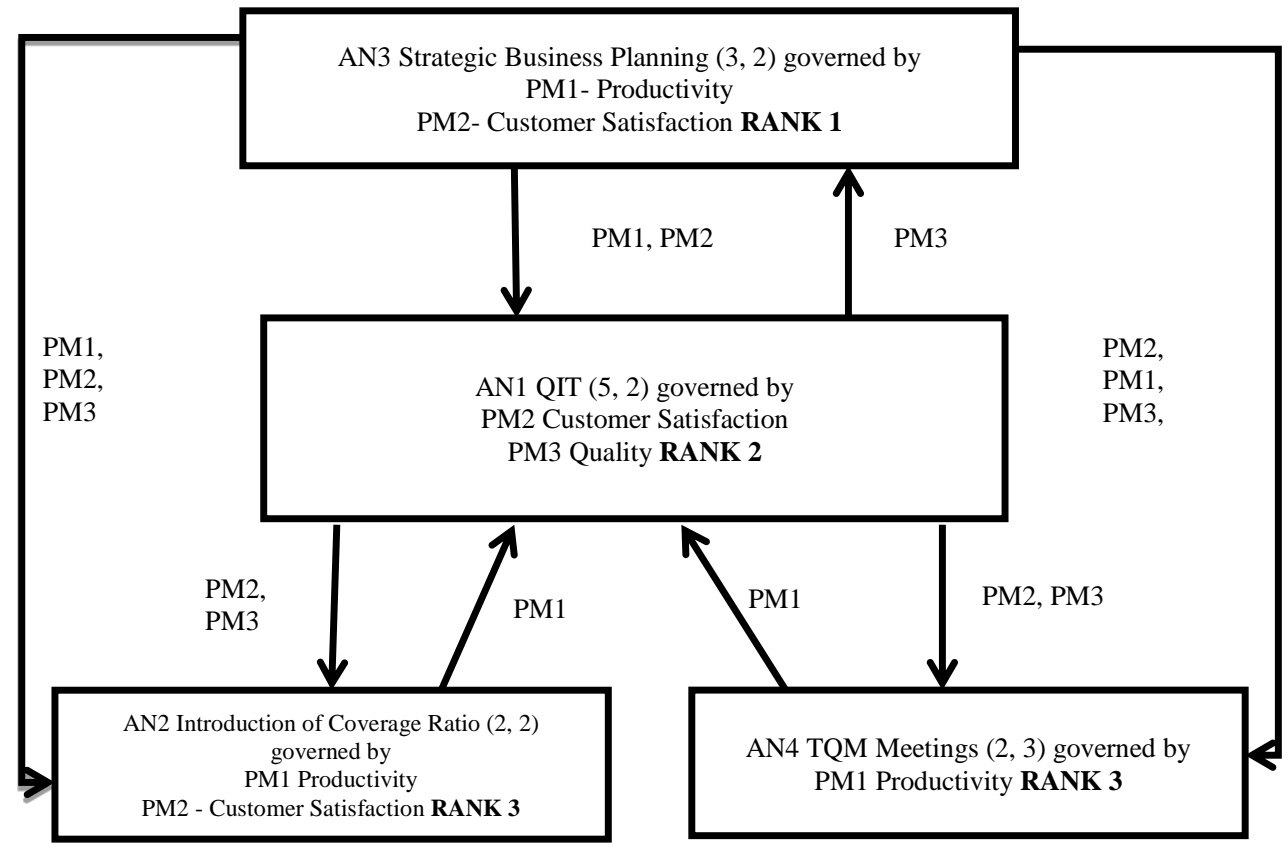

Figure 2. IRP model for actions with reference to performance. 


\subsubsection{Validation of the Model}

Validating the model is the final step and it checks whether the interpretations made are correct by making a system walkthrough of the interpretive matrix. The validating model also checks whether all the relevant alternatives in the model are included through reviews and reassessment. CrossValidation of Dominance is evaluated by (Sushil, 2017a).

(i) Checking whether the summation of all net dominance for all the variables is equal to 0 . From Table 27 and Table 28, it can be seen that the summation of all the net dominance interactions is equal to 0 .

(ii) Employing more than one expert for different interpretations and cross-checking the rankings. Whether interactions are rightly evaluated is checked by employing system diagraphs. The digraph employed for validating dominance relationships should display a unidirectional transitive relationship. No feedback loop or cycle across the system graph will be entertained. The system graph for checking the internal validity of the paired comparison is shown in Figure 3 and Figure 4 shows the dominance system graph used for checking the validity of the pairwise comparison of actors with reference to various processes and actions with reference to performances. Since the system digraph model shows the unidirectional transitive relationship without forming any feedbacks or loops among the dominance interactions, the above interpretive ranking process model is validated.

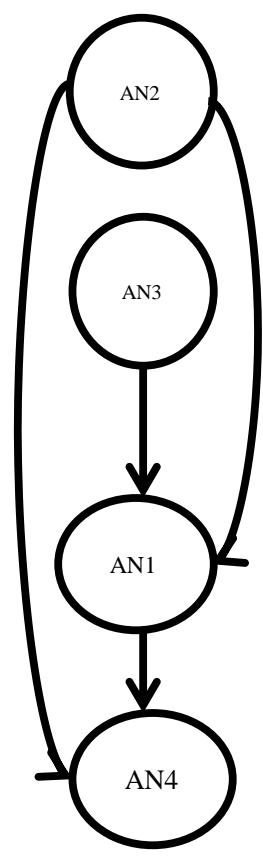

PERFORMANCE PM1

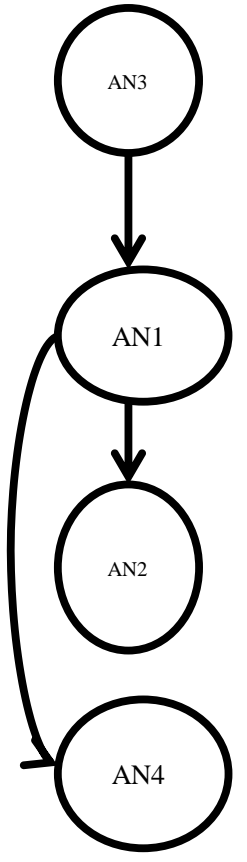

PERFORMANCE PM2

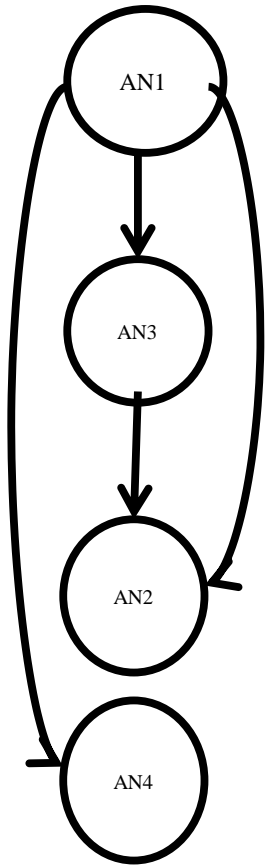

PERFORMANCE PM3

Figure 3. Dominance system graph to check the validity of pair wise comparison of actors with reference to various process. 


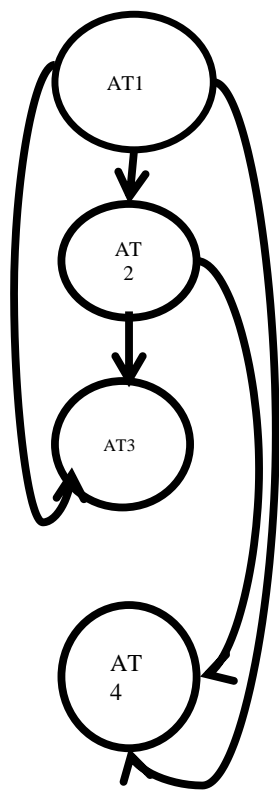

PROCESS PR1

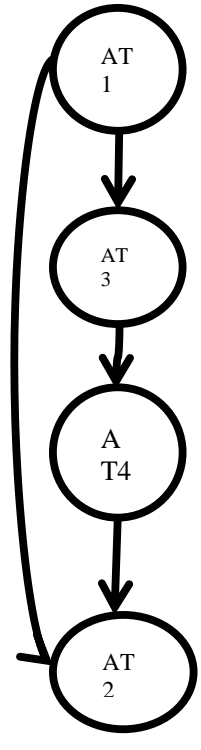

PROCESS PR2

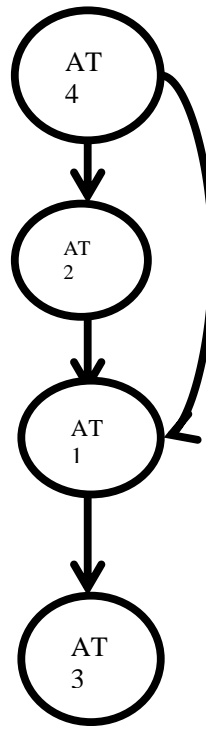

PROCESS PR3

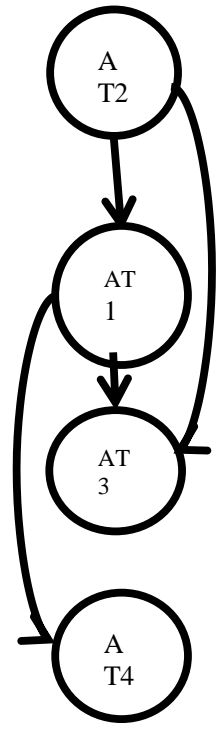

PROCESS PR4

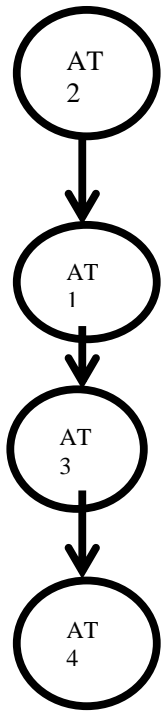

PROCESS PR5

Figure 4. Dominance system graph to check the validity of pair wise comparison of actions with reference to various performance.

\section{Conclusions}

This paper presents a holistic approach to study an organization for multi-criteria decision making. The carefully selected flexible elements within the organization form the elements of the SAP LAP framework, Stiff competition is the input constituent of the various other situation, influencing the other elements as per the self-interaction matrix. Thus, stiff competition is given special emphasis to frame the key issues related to or associated with it that lead to various learning issues. From the SAP-LAP framework it can be seen that the CEO of the organization is the most linked actor since it is the sole motivating force behind implementing the policy deployment as reported (Ahmed, 2016; Cwiklicki, 2010; Dale, 1990; Kumar and Gupta, 2021). Strategic planning is the most linked process that helps in achieving competence up-gradation and manufacturing cost reduction, this is consistent with results reported by (Ho and Soebandrija, 2021; Kak, 2004). CEO plays an important role in the formulation of the vision, mission, and strategic planning of the organization, on the other hand, the plant head works as care taker of these framed policies and looks after the deployment. The suggested action of quality improvement teams will help in achieving all the strategic objectives of the case organization through quality control and in-house technological Development, these findings are consistent with the results reported by (Husain et al., 2002; Kumar and Gupta, 2020; Marksberry, 2011; Nicholas, 2016). The ranks obtained with the help of the eIRP approach give an idea about the prioritization of actors with reference to processes and actions with reference to performance measures. The ranking of actors briefly depicts the situations where these actors dominate others for a particular reference process. The analysis revealed that the plant head dominates the other actors of the organization in most of the processes as is mainly responsible for the actual deployment of policies on the ground. The interaction of actors with the process helps in building core competence, achieving profitability, and reduction of MUDAs through workforce optimization. The interplay of a situation with the process helps in 
deciding the various steps that have to been taken with a response to changing market needs and rising customer demands thus maintaining the aspect of flexibility. Finally, the brunt of recommended actions on expected recital is evaluated using the cross-interaction matrix that can help in achieving prospective business. On similar lines, one can conclude from the ranking of actions that AN3: Strategic planning is the top-ranked action among the others. Strategic planning helps in mapping the desired objectives with the processes along with fixing the roles of actors in the various transformation processes.

Thus, it can be said that the SAP-LAP framework can help to decide the various constraints in which the actors have to act for policy formulation or managerial decisions of the firm. The basic LAP framework of the organization is shown in Figure 5. The study also depicted how the SAPLAP elements and cross interaction matrices used for the policy deployment process in a case organization can effectively be used to generate the efficient IRP model using step by step illustrated methodology. The ranks obtained through the efficient IRP model will facilitate the policymakers in the formulation of better decisions and implementation of key policies. The e-IRP model emphasizes the prioritization of actors for processes and actions concerning performance. The cross-interaction matrices obtained from the interrelationship among the elements of the SAPLAP framework are used as a base for paired comparison. The major advantage of the e-IRP model is that it integrates the analytical logic of the rational choice process with the decision-making strategy of the intuitive process at the elemental level, thus making the process of comparison efficient. According to the e-IRP model findings, the plant head plays the most significant role in the execution of the strategic plans or policies and the govt of India is the least ranked actor with reference to an assortment of the process necessary for the implementation of policy deployment in the given case organization. Consequently, the action of strategic business plan meetings carries the highest weightage with reference to the different key performance indicators.

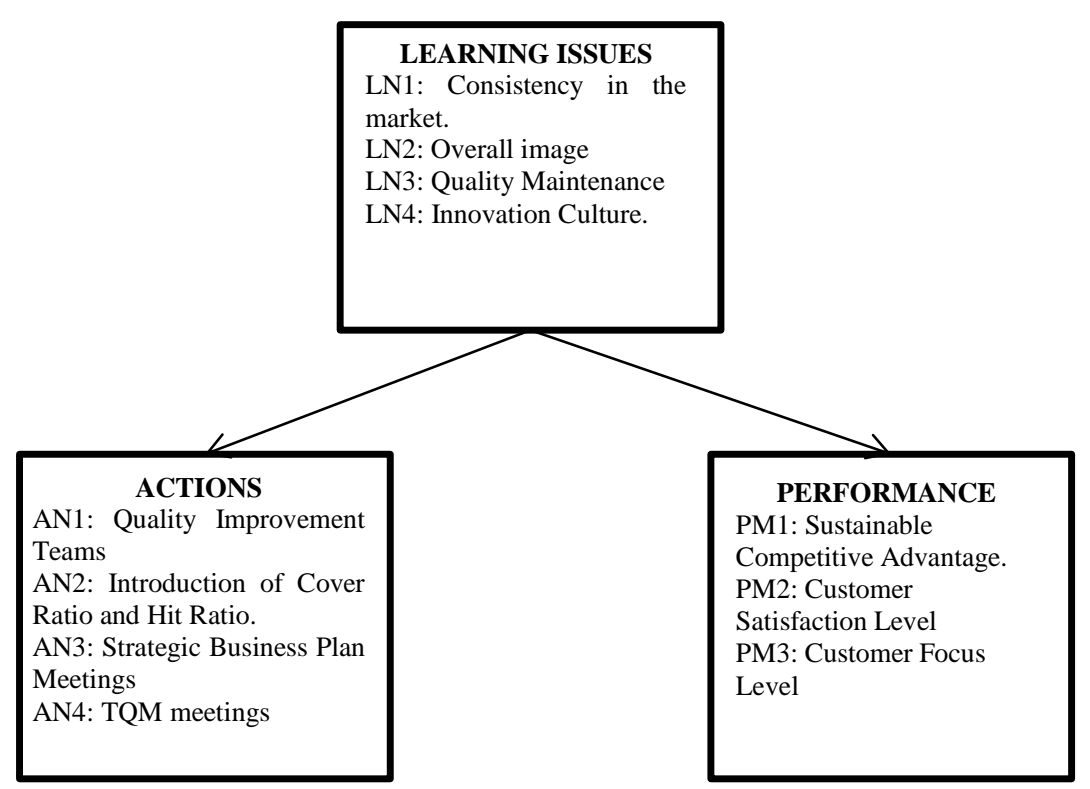

Figure 4. Generic LAP framework. 
This paper provides a novel approach for addressing the flexible issues of policy deployment using the SAP-LAP and e-IRP model for the organizations that are becoming more flexible and adapting to the ever-changing demands of the customers.

\section{Managerial Implications}

This study offers the implication in the following manner

(i) Policy deployment being an inherent working principle of an organization require precise decision making. More often these decisions are based on the outcome of the interactions with the various factors of interest. These interactions can be predicted by the managers with the help of the SAP-LAP process.

(ii) A ready reference in the form of Knowledge base will be available to the managers.

(iii) Decision-making process can be improved.

\section{Limitations of the Study}

This case study offers a theoretical framework and is subjected to validation by implementing in a real-life situation.

\section{Future Scope}

The study can be extended by integrating with other modelling techniques like TISM, SEM, etc.

Conflicts of Interest

There is no conflict of interest.

Acknowledgments

The authors like to thank to organization XYZ Ltd. for providing support.

\section{References}

Ahmed, H.O.K. (2016). A proposed systematic framework for applying hoshin kanri strategic planning methodology in educational institutions. European Scientific Journal, 12(16), 158-194.

Akao, Y. (2004). Hoshin Kanri: policy deployment for successful TQM. Taylor \& Francis Group.

Alley, H., Bacinello, C.P., \& Hipel, K.W. (1979). Fuzzy set approaches to planning in the grand river basin. Advances in Water Resources, 2, 3-12.

Arshinder, Kanda, A., \& Deshmukh, S.G. (2007). Supply chain coordination issues: an SAP-LAP framework. Asia Pacific Journal of Marketing and Logistics, 19(3), 240-264.

Cwiklicki, M. (2010). TQM methods applied in the Hoshin Kanri management system. Business and Management, II, 815-821.

Dale, B.G. (1990). Policy deployment. The TQM Magazine, 2(6), EUM0000000003052. https://doi.org/10.1108/eum0000000003052.

Garg, A., \& Deshmukh, S.G. (2010). Engineering support issues for flexibility in maintenance: An SAP-LAP framework. Asia Pacific Journal of Marketing and Logistics, 22(2), 247-270.

Gupta, P.J., \& Suri, P.K. (2018). Analysing the influence of improved situation, capability level of actors and flexible process workflow on public value of e-governance projects in India. Global Journal of Flexible Systems Management, 19(4), 349-372. 
Ho, H.C., \& Soebandrija, K.E.N. (2021). Hoshin Kanri's strategic planning methodology through Dijkstra algorithm with in industrial engineering and stakeholder perspectives. In IOP Conference Series: Materials Science and Engineering (Vol. 1115, No. 1, P. 012038). IOP Publishing. West Java, Indonesia.

Husain, Z., Sushil, \& Pathak, R.D. (2002). A technology management perspective on collaborations in the Indian automobile industry: a case study. Journal of Engineering and Technology Management, 19(2), 167-201.

Jolayemi, J.K. (2008). Hoshin kanri and hoshin process: A review and literature survey. In Total Quality Management and Business Excellence, 19(3), 295-320.

Kabra, G., \& Ramesh, A. (2015). Analyzing ICT issues in humanitarian supply chain management: a SAPLAP linkages framework. Global Journal of Flexible Systems Management, 16(2), 157-171.

Kak, A. (2004). Strategic management, core competence and flexibility: learning issues for select pharmaceutical organizations. Global Journal of Flexible Systems Management, 5(4), 1-15.

Kondo, Y. (1998). Hoshin Kanri- a participative way of quality management in Japan. TQM Magazine, 10(6), 425-431.

Kumar, S., \& Gupta, P. (2020). Case study on business excellence issues of an Indian automobile manufacturer using SAP-LAP framework. International Journal on Emerging Technologies, 11(3), 911918.

Kumar, S., \& Gupta, P. (2021). Implementation of cost management initiatives through TQM in an Indian automotive industry: A Case Study. International Journal of Disaster Recovery and Business Continuity, 12(1), 25-38.

Lee, R.G., \& Dale, B.G. (1998). Policy deployment: An examination of the theory. International Journal of Quality and Reliability Management, 15(5), 520-540.

Majumdar, S.K., \& Gupta, M.P. (2001). E-Business strategy of car industry: SAP-LAP analysis of select case studies. Global Journal of Flexible Systems Management, 2(3), 13-28.

Malik, S., Maheshwari, G.C., \& Singh, A. (2019). Understanding financial inclusion in India: A theoretical framework building through SAP-LAP and efficient IRP. Global Journal of Flexible Systems Management, 20(2), 117-140.

Manos, A. (2010). Hoshin promotion: Advice on making this work for your organisation. Six Sigma Forum Magazine, 7-14.

Marksberry, P.W. (2011). The theory behind Hoshin: A quantitative investigation of toyota's strategic planning process. International Journal of Business Innovation and Research, 5(3), 347-370.

Matzler, K., Hinterhuber, H.H., Bailom, F., \& Sauerwein, E. (1996). How to delight your customers. Journal of Product and Brand Management, 5(2), 6-18.

Mulligan, P., Hatten, K., \& Miller, J. (1996). From Issue-based planning to Hoshin: different styles for different situations. Long Range Planning, 29(4), 473-484.

Nicholas, J. (2016). Hoshin Kanri and critical success factors in quality management and lean production. Total Quality Management \& Business Excellence, 27(3-4), 250-264.

Rewers, P., Trojanowska, J., \& Chabowski, P. (2016). Tools and methods of lean manufacturing- a literature review. In Proceedings of 7th International Technical Conference Technological Forum 2016 (pp. 135139). Scientific Information System of the Poznań University of Technology. Prague, Czech Republic.

Kumar, P.S., \& Anbanandam, R. (2020). Theory building on supply chain resilience: a SAP-LAP analysis. Global Journal of Flexible Systems Management, 21(2), 113-133.

Sushil. (2001a). SAP-LAP framework. Global Journal of Flexible Systems Management, 2(1), 51-55. 
Sushil. (2001b). SAP-LAP models. Global Journal of Flexible Systems Management, 2(2), 55-61.

Sushil. (2005). Interpretive matrix: a tool to aid interpretation of management and social research. Global Journal of Flexible Systems Management, 6(2), 27-30.

Sushil. (2017a). Interpretive ranking process. Global Journal of Flexible Systems Management, 10(4), 1-10.

Sushil. (2017b). SAP-LAP linkages- a generic interpretive framework for analyzing managerial contexts. Global Journal of Flexible Systems Management, 10(2), 11-20.

Sushil. (2019). Efficient interpretive ranking process incorporating implicit and transitive dominance relationships. Annals of Operations Research, 283(1-2), 1489-1516.

Tennant, C., \& Roberts, P. (2001). Hoshin Kanri: implementing the catchball process. Long Range Planning, 34(3), 287-308.

Thakkar, J., Kanda, A., \& Deshmukh, S.G. (2008). Interpretive structural modeling (ISM) of it-enablers for Indian manufacturing smes. Information Management and Computer Security, 16(2), 113-136.

Watson, G. (1991). Understanding Hoshin Kanri. In Y. Akao (Ed.) Hoshin Kanri: Policy deployment for successful TQM. In UCambridge, MA: Productivity Press.

Witcher, B., \& Butterworth, R. (1999). Hoshin Kanri: How xerox manages. Long Range Planning, 32(3), 323-332.

Witcher, B.J., \& Butterworth, R. (1997). Hoshin Kanri: A preliminary overview. Total Quality Management, $8(2-1), 319-323$.

Witcher B.J. (2014). Hoshin Kanri. Perspectives on Perfomance, 11(1), 16-24.

Witcher, B.J., \& Butterworth, R. (2001). Hoshin Kanri: Policy management in japanese-owned UK subsidiaries. Journal of Management Studies, 38(5), 651-674.

Xerox, R. (1992). We win europe's top quality award. Vision: The House Magazine of Rank Xerox Mitcheldean, 216. 